\title{
A relação entre a manifestação artístico-cultural e a criação dos direitos fundamentais
}

\section{The relationship between artistic-cultural manifestation and the creation of fundamental rights}

\author{
Jefferson Lopes Custódio $^{1 *}$, Arielle Arry Carvalho ${ }^{2}$, Francisco Mauro Ferreira Liberato ${ }^{3}$
}

\begin{abstract}
RESUMO
Por meio deste artigo, tem-se a proposição de analisar a relação entre a manifestação artístico-cultural e a criação dos direitos fundamentais estabelecidos em Textos Constitucionais, revelando a influência de um sobre o outro. Nessa perspectiva, provocou-se um diálogo entre a criação artístico-cultural humana, especialmente a partir do século XVIII, com o sistema jurídico protetor que garante a salvaguarda dos direitos e garantias individuais. Com isso, é razoável enxergar uma relação simbiótica das iniciativas artísticas com os direitos fundamentais positivados nas Constituições, os quais foram relevantes no percurso histórico da sociedade contemporânea, bem assim contribuíram para o desenvolvimento dos povos. Na ocasião, desenvolveu-se uma pesquisa bibliográfica, com ênfase qualitativa, utilizando-se obras, trabalhos acadêmicos, consulta às Constituições e complementando o estudo com dados secundários. Dessa maneira, espera-se confirmar a hipótese de que a produção artístico-cultural, consolidada a partir da Revolução Francesa, influenciou na formação dos direitos fundamentais em todas as suas dimensões, incorporando-os ao patrimônio comum da humanidade.
\end{abstract}

Palavras-chave: Manifestação artístico-cultual; Relação; Direitos fundamentais.

\begin{abstract}
Through this article, we propose to analyze the relationship between artistic-cultural expression and the creation of fundamental rights established in Constitutional Texts, revealing the influence of one on the other. From this perspective, a dialogue was provoked between human artistic-cultural creation, especially from the 18th century, with the protective legal system that guarantees the safeguarding of individual rights and guarantees. With this, it is reasonable to see a symbiotic relationship of artistic initiatives with the fundamental rights affirmed in the Constitutions, which were relevant in the historical course of contemporary society, as well as contributing to the development of peoples. In the hypothesis, a bibliographical research was developed, with a qualitative emphasis, using works, academic works, consult the Constitutions and complementing the study with secondary data. In this march, it is expected to confirm the hypothesis that the artistic-cultural production consolidated from the French Revolution, influenced the
\end{abstract}

\footnotetext{
${ }^{1}$ Universidade de Fortaleza (UNIFOR). Programa de pós-graduação em Direito (PPGD). *Email: jeffersonlopescustodio@gmail.com.

${ }^{2}$ Faculdade Vale do Jaguaribe (FVJ). E-mail: Arielleadv-ce@ hotmail.com.

${ }^{3}$ Tribunal de Justiça do Estado do Ceará. Universidade de Fortaleza (UNIFOR). PPGD. E-mail: maurolib@uol.com.br.
} 
formation of fundamental rights in all its generations, incorporating them into the common heritage of humanity.

Keywords: Artistic-cultural manifestation; Relationship; Fundamental rights.

\section{INTRODUÇÃO}

A história da arte conta a formação civilizatória dos povos, revelando a forma eficaz da expressão humana. Ela foi necessária desde o período pré-histórico, no tempo da pedra lascada, porque favoreceu uma forma de comunicação e interação entre os homens (MENDONÇA, 2019). Assim, a atividade artística está presente na linguagem, no discurso, na arquitetura, na dança, na música, na engenharia, na pintura, na poesia, na matemática, no direito, dentre outras áreas e, dessa forma, registra o momento sóciopolítico-cultural de cada época.

Conceituar arte é tarefa das mais difíceis, por isso Tolstoi (2002) se restringiu a sugerir que ela não era somente um objeto de prazer estético, mas sobretudo um meio de intercâmbio e integração humana. $\mathrm{O}$ autor russo destacou ainda que a arte surge das coisas simples e serve para unir as pessoas, tornando-se uma verdadeira comunhão de sentimentos e atividades desenvolvidas na capacidade que umas tinham de tocar os sentimentos das outras.

Kant (2003, p. 272) entende que "el arte bello, por el contrario, es una forma de representación que es teleológica por sí misma y que a pesar de carecer de fin fomenta, sin embargo, la cultura de las capacidades del ánimo para una comunicación sociable". Assim, a arte foi se expandindo e contribuiu para o surgimento de diversos segmentos, como a literatura, teatros, favorecendo a formação de centros urbanos complexos, mas acompanhados de desigualdades sociais e conflitos entre os indivíduos, ou entre estes e o Estado.

Assim, o binômio arte e cultura está intimamente ligado, restando uma missão difícil a separação conceitual entre as duas áreas. Além disso, seria razoável inferir que as normas jurídicas, notadamente aquelas que representam direitos e garantias dos homens, são expressões artístico-culturais, haja vista que os princípios e regras jurídicas 
traduzem atos da criação humana especialmente em favor dos direitos fundamentais dos indivíduos, em todas as suas dimensões.

Fazendo frente contra a sociedade europeia do século XVIII, Rousseau (1999) criticou as ciências, as letras e as artes porque, segundo o filósofo suíço, surgiram fortemente a partir da vida em sociedade, ocasião em que essas criações humanas corromperam o indivíduo, retirando-lhe de seu estado do bom selvagem, promovendo toda sorte de desigualdade social. À respeito do tema, o filósofo radicado na França avaliou que:

Enquanto o Governo e as leis atendem à segurança e ao bem-estar dos homens reunidos, as ciências, as letras e as artes, menos despóticas e talvez mais poderosas, estendem guirlandas de flores sobre as cadeias de ferro de que estão eles carregados, afogam-lhes o sentimento dessa liberdade original para a qual pareciam ter nascido, fazem com que amem sua escravidão e formam assim o que se chama povo policiados (Rousseau, 1999, p. 11-12).

Nesse passo, com a formação de grupos sociais em centros urbanos, houve a necessidade de estabelecimento de um sistema jurídico de controle social para disciplinar o direito à propriedade, à liberdade e, sobretudo, à liberdade dos indivíduos, sedimentando a importância do Estado. Em linhas gerais, o direito é um acordo por meio qual os homens realizam pactos para uma garantia de uma vida digna e segura, bem assim para subjugar as suas vontades individuais em prol de um sistema em que vigore o interesse coletivo.

Sobre o tema em debate, importante distinguir as expressões: direitos humanos, direitos fundamentais e direitos da pessoa humana. A diferença não reside apenas em questão terminológica ou principiológica, tanto que os estudiosos do direito não são unânimes quando enfrentam esses termos. Silva (2001) ensina que direitos humanos é a expressão preferida nos documentos internacionais e complementa:

Contra ela [expressão direitos humanos], assim, como contra a terminologia direitos do homem, objeta-se que não há direito que não seja humano ou do homem, afirmando-se que só o ser humano pode ser titular de direitos. Talvez já não mais assim, porque, aos poucos, se vai formando um direito especial de proteção aos animais (SILVA, 2001, p. 180).

Bobbio (1992) destaca que são direitos fundamentais todos aqueles que não são suspensos em nenhuma circunstância, nem mesmo negados para determinada categoria de pessoas. $\mathrm{O}$ autor sustenta ainda a distinção entre direitos do homem unicamente naturais, que equivalem aos direitos humanos, com os direitos do homem positivados, estes seriam os direitos fundamentais estabelecidos em Textos Constitucionais, de forma 
que, quando os direitos do homem eram considerados unicamente como direitos naturais, a única defesa possível contra a sua violação pelo Estado era um direito igualmente natural, o chamado "direito de resistência" (BOBBIO, 1992, p. 31).

Mas é importante advertir, contudo, que os direitos fundamentais não são aplicados de forma absoluta, até porque, em alguns casos, há colisão entre direitos de mesma magnitude, o que deve ser resolvido pelo critério da ponderação ou pelo princípio da proporcionalidade (ALEXY, 2015), mas de modo que um princípio prevaleça, circunstancialmente, sobre o outro; o que pode ocorrer o inverso em outra situação fáticojurídica.

José Afonso da Silva (2003, p. 178) identifica nos direitos fundamentais uma nota de essencialidade, bem assim que, no "qualificativo fundamentais", acha-se a indicação de que se trata de situações jurídicas sem as quais o homem não se realiza, tampouco garante a sua convivência e, até mesmo, a sua sobrevivência.

Enfim, seria razoável sintetizar a ideia de que os direitos fundamentais são construídos a partir de dispositivos constitucionais; enquanto os direitos humanos são formalizados a partir de tratados internacionais acordados entre os Estados soberanos. E os direitos da pessoa humana estão relacionados com a noção jusnaturalista, desenvolvida a partir de uma norma intersubjetiva universalmente aceita.

Assim, partindo-se da premissa de que o direito é uma expressão artístico-cultural de um determinado grupo social, pode-se assentar que os direitos fundamentais, convencionados num certo período da história, representam uma manifestação de uma sociedade numa determinada época, tonificando-se a ideia de que a manifestação artístico-cultural se exprime por meio de iniciativas populares, que legitimam a formação do Poder Legislativo, que reproduz as aspirações do povo por meio de normas.

Por esta ótica, perceba que a cada surgimento de dimensão (ou geração) dos direitos fundamentais, a partir do final do século XVIII, quando se conheceu a sua primeira dimensão, a sociedade atravessava algumas turbulências político-sociais, cujas hipóteses serão apresentadas no próximo tópico deste artigo. Daí surge o interesse em se estabelecer uma relação com as atividades artístico-culturais de cada estação com a criação dos correspondentes direitos fundamentais, objeto da presente pesquisa.

É relevante destacar ainda que os direitos fundamentais visam, essencialmente, à proteção do cidadão contra os abusos de autoridades estatais (relação vertical), bem como na sua relação com seus pares e, neste último caso, é aplicada a teoria da eficácia 
horizontal dos direitos fundamentais, que reclama a incidência dos direitos fundamentais nas relações privadas, entendimento aceito amplamente na doutrina e jurisprudência (SILVA, 2005).

Outro ponto singular nesta linha de retroalimentação entre a manifestação artísticocultural e o direito, refere-se à busca do belo, do justo e do perfeito. Com efeito, é algo sublime aceitar a afirmação segundo a qual um juiz se utiliza de tais atributos originados da arte para atingir a beleza, a justeza e a perfeição na sua função interpretativa na aplicação da lei, notadamente para reconhecer um direito fundamental a um indivíduo.

Por tudo isso, os direitos fundamentais estão fortemente associados às manifestações artístico-culturais, que assumem diferentes formas e se estendem às diversas modalidades da vida humana, marcando a sua importância no conhecimento, na literatura, no teatro, na música e, especialmente, no direito, a partir do qual é criado um sistema jurídico que tutela o indivíduo contra os abusos e ilegalidades.

\section{JUSTIFICATIVA, OBJETIVO E METODOLOGIA}

Superadas as considerações anteriores, chega-se o momento de se indagar como e por que a expressão artístico-cultural dialoga com o direito, sobretudo no plano dos direitos fundamentais. Nesse passo, o binômio arte-cultura e o direito imitam a vida. Por óbvio, não ocupam uma mesma área, uma vez que a manifestação artístico-cultural não agrega princípios e regras jurídicas que informam o direito, e este não goza da liberdade subjetiva de criação conferida às atividades artísticas e culturais.

Ainda, não é raro o operador do direito encontrar inspiração ou fundamentação de suas peças jurídicas em obras de arte, como no livro, no filme, na música, no poema ou numa exposição fotográfica e tudo isso agrega a atividade artístico-cultural. Igualmente, apenas as palavras das normas não fornecem ou inspiram o julgador na solução da controvérsia, sendo necessário se valer da arte para dirimir a querela formada entre os litigantes. E esta situação fortalece a versão de que o direito encontra as respostas de suas dúvidas na arte, que representa a própria vida humana.

Assim, apesar das peculiaridades de um e outro, a arte, a cultura e o direito são indissociáveis e se complementam, mesmo que este orbite predominantemente no campo da objetividade e da despersonalização, e as primeiras atuem no plano subjetivo. Enfim, 
os institutos ora estudados operam com as expressões humanas, partilhando linguagens e símbolos, a fim de interpretar, descrever e transformar o mundo.

Por estas razões, extrai-se a relevância do tema em debate, que envolve assuntos que interessam à população. Com efeito, os direitos fundamentais estão fortemente associados às manifestações artístico-culturais, que assumem diferentes formas e se estendem a diversas modalidades da vida humana, marcando a sua importância no conhecimento, na literatura, no teatro, na música e, notadamente, no direito, a partir do qual é criado um sistema protetivo que tutela o indivíduo contra os abusos e ilegalidades.

Nessa perspectiva, propôs-se uma análise da relação simbiótica entre a manifestação artístico-cultural e a criação dos direitos fundamentais organizados em Textos Constitucionais, de modo a provocar um diálogo da criação humana, a partir do século XVIII (Revolução Francesa), com o sistema jurídico protetor que garante a salvaguarda dos direitos e garantias individuais.

$\mathrm{Na}$ hipótese, desenvolveu-se uma pesquisa do tipo bibliográfica, de natureza qualitativa, que envolva uma abordagem teórica e exploratória. O referencial teórico será embasado na legislação constitucional, na doutrina e em obras artístico-culturais de autores, especialmente no plano da escrita, da filosofia, da música, e da pintura. Ainda, sob o aspecto bibliográfico, haverá também suporte em dados secundários, para auxiliar a pesquisa desenvolvida neste artigo.

\section{AS MANIFESTAÇÕES ARTÍSTICO-CULTURAIS E OS DIREITOS FUNDAMENTAIS DE $1^{\mathrm{a}}, 2^{\mathrm{a}}, 3^{\mathrm{a}}, 4^{\mathrm{a}}$ E $5^{\mathrm{a}}$ DIMENSÃO}

A norma constitucional tem como finalidade precípua a concretização dos direitos fundamentais. E, sob uma perspectiva estética, a concretização dos direitos fundamentais consiste na magnus opus do direito enquanto arte (XEREZ, 2014, p. 256), levando-se em conta que as produções humanas estão relacionadas com os costumes, crenças, saberes e os modos de viver da população.

Concernente aos direitos fundamentais de primeira dimensão, é importante recordar que a Europa, no final do século XVIII, atravessava uma situação econômica, política e social delicada, o que desencadeou a Revolução Francesa, que provocou a queda do regime absolutista, dando início à Idade Contemporânea. A partir de então, fortaleceramse as discussões sobre as liberdades do homem (CANOTILHO, 2008). 
No período pré-revolução surgiram movimentos como o Iluminismo e o Enciclopedismo, de maneira que as artes e os pensamentos produzidos pelos intelectuais da época influenciaram as parcelas desfavorecidas da população, dentre elas a burguesia, a fim de extirpar o Antigo Regime. Neste cenário, a liberdade do homem surgiu como uma das principais bandeiras do movimento revolucionário, o que representava, na época, uma importante conquista do indivíduo, porque libertava o mundo do obscurantismo.

Condizente pontuar que, durante o Século das Luzes, surgiram filósofos, como Voltaire e Rousseau, e artistas, como Wolfgang Amadeus Mozart e Jean-Pierre Louis Laurent, que influenciaram na criação dos direitos fundamentais de primeira dimensão (ou geração), por meio da escrita, música e pintura, com suas ideias centradas na liberdade e na vida digna do homem, cujos paradigmas irradiaram efeitos no mundo, particularmente no Ocidente.

Realmente, algumas manifestações artístico-culturais de Voltaire e Rousseau ${ }^{4}$, conhecidas mundialmente, tratavam exatamente do tema corrente na época: a liberdade humana. No caso, Voltaire pregava que o homem nasceu livre e assim deveria permanecer, inclusive com poderes para destronar tiranos; ao passo que Rousseau era defensor da soberania popular, o que naturalmente inclui o tema liberdade (DOLHNIKOFF, 2015).

Dessa maneira, os direitos fundamentais de primeira dimensão foram construídos, também, por meio de movimentos de conscientização da população a partir de iniciativas artístico-culturais. Sobre a temática, Bonavides vazou o seguinte entendimento:

Os direitos de primeira geração são os direitos de liberdade, os primeiros a constarem do instrumento normativo constitucional, a saber, os direitos civis e políticos, que em grande parte correspondem, por um prisma histórico, àquela fase inaugural do constitucionalismo do Ocidente (BONAVIDES, 2017, p. 577).

Superados os primeiros grandes problemas do homem, no início da Idade Contemporânea, relacionados à sua liberdade, surgiu a necessidade de conquista dos direitos fundamentais de segunda dimensão, desta vez, associados às liberdades positivas do indivíduo. Na ocasião, a Europa atravessava o período da Revolução Industrial, cujo auge ocorreu entre os séculos XIX e XX, momento em que eclodiram reivindicações

\footnotetext{
${ }^{4}$ Confira o "Discurso sobre as ciências e as artes" e "Discurso Sobre a Origem e os Fundamentos da Desigualdade Entre os Homens", ambas de Rousseau.
} 
associadas a direitos sociais básicos da população, como alimentação, educação, saúde e trabalho. Sarmento bem sintetiza esse período da história:

As Constituições do México (1917) e de Weimar (1919) trazem em seu bojo novos direitos que demandam uma contundente ação estatal para sua implementação concreta, a rigor destinados a trazer consideráveis melhorias nas condições materiais de vida da população em geral, notadamente da classe trabalhadora. Fala-se em direito à saúde, à moradia, à alimentação, à educação, à previdência etc. Surge um novíssimo ramo do Direito, voltado a compensar, no plano jurídico, o natural desequilíbrio travado, no plano fático, entre o capital e o trabalho. O Direito do Trabalho, assim, emerge como um valioso instrumental vocacionado a agregar valores éticos ao capitalismo, humanizando, dessa forma, as até então tormentosas relações jus laborais. No cenário jurídico em geral, granjeia destaque a gestação de normas de ordem pública destinadas a limitar a autonomia de vontade das partes em prol dos interesses da coletividade (Sarmento, 2006, p. 19).

Nesse contexto, conveniente trazer à colação a pintura "O quarto estado" ", do artista italiano Giuseppe Pellizza, concluída em 1901, em que é exposta a difícil situação do proletariado, que entra em greve, ocupando a praça da Volpedo, na Itália, cuja obra simboliza a luta dos trabalhadores pelos seus direitos sociais.

Uma das referências sobre os direitos sociais, típicos dos direitos fundamentais de segunda geração, a Constituição de Weimar sofreu forte influência de obras de autores como Carl Marx, Hans Kelsen, Carl Schmitt e Erich Kauffmann, assim como de intelectuais como Thomas e Heinrich Mann e Segmund Freud (RODAS, 2019). De fato, algumas iniciativas humanas, como a escrita, representam uma manifestação artísticocultural e um instrumento de realização individual e coletiva que influencia permanentemente na formação social, política, jurídica e cultural de comunidades.

Com efeito, no período pós Primeira Guerra Mundial, verificou-se um crescimento desenfreado do capitalismo, com acúmulos de riquezas e desigualdades sociais, que provocaram diversas reivindicações populares, discutindo os fundamentos da propriedade e impondo às autoridades a formalização da função social da propriedade. Por isso, surgiram autores, como Carl Marx, que defendiam os direitos sociais dos trabalhadores, cujas obras representam uma manifestação sociocultural em favor dos operários.

Assim, uma vez mais, a arte e a cultura se fizeram presentes neste importante momento histórico ocorrido no mundo, até porque a manifestação humana que deflagrou o movimento revolucionário industrial, em busca de direitos sociais, foi impulsionada

\footnotetext{
${ }^{5}$ Pode ser visualizada diretamente no endereço: https://pt.wikipedia.org/wiki/O_Quarto_Estado.
} 
pela soma dos dotes artísticos de personalidades, a partir dos quais se originou toda a inspiração e sensibilidade para posturas reivindicatórias que, posteriormente, surtiram efeitos na ordem jurídica, com a formalização de direitos fundamentais de cunho social.

E mais, a revolução tecnológica, decorrente da ascensão do setor industrial, na realidade, significou uma transformação sociocultural sofrida pela população europeia, irradiando efeitos em todo o planeta. Aliás, a iniciativa humana é uma materialização do dom artístico que cada um carrega consigo, como também decorrente de sua energia para reivindicar direitos. $\mathrm{E}$ os atos revolucionários ocorreram porque o homem criava e produzia riquezas mas dela não usufruía, gerando toda sorte de descontentamento e desigualdade social.

Após a Segunda Guerra Mundial, em meados do século XX, que deixou diversos prejuízos à humanidade, razão por que surgiu a necessidade de implementação de direitos fundamentais de terceira geração, como os direitos difusos, relacionados ao desenvolvimento, ao meio ambiente, à fraternidade e à paz, muito embora, neste último caso, alguns autores, como Bonavides (2017), enxergam o direito fundamental à paz como enquadrado na sua quinta dimensão.

Sarlet (2007) esclareceu esse momento histórico, como se fosse o resultado de novas e progressivas reivindicações fundamentais da pessoa humana, provocadas, dentre outras razões, pelo impacto tecnológico, pelo estado crônico da beligerância dos homens, como também pelo processo de descolonização do Segundo Pós-Guerra e suas catastróficas consequências, acarretando cicatrizes na esfera dos direitos fundamentais dos indivíduos.

Oportuno evidenciar uma relevante obra do modernista Carlos Drummond de Andrade que, por meio de A Rosa do Povo (1945), expôs poeticamente os horrores da Segunda Guerra Mundial, reafirmando a importância do artista como sujeito ativo e propalador de críticas contra os atos devastadores dos homens, que geram desequilíbrio e prejuízo à sobrevivência dos povos (ANDRADE, 2012).

Ademais, as manifestações artístico-culturais dos intelectuais são lidas e assimiladas por autoridades que detêm o poder de decisão, de maneira que os seres humanos não vivem dissociados das manifestações artístico-culturais propaladas nos grupos sociais. É dizer, as criações humanas contribuem na formação de cada indivíduo e, por isso, são levadas em consideração na criação dos direitos fundamentais pelos legisladores. 
Como reforço, ilustre-se o poema "Rosa de Hiroshima", escrita por Vinícius de Moraes em 1946, transformado em música, na voz de Ney Matogrosso, e que tece severas críticas à bomba atômica lançada pelos Estados Unidos sobre as cidades japonesas de Hiroshima e Nagasaki, pondo fim à Segunda Guerra Mundial, mas que representou um triste capítulo na história da humanidade (MOREAES, 2009). Cuida-se de uma obra de alto relevo cultural, conhecida e divulgada em diversos países.

No plano internacional, os Estados-membros acordaram em 10 de dezembro de 1948 (depois da Segunda Guerra), por meio da Assembleia Geral das Organizações das Nações Unidas (ONU), dentre outras disposições, que toda pessoa tem direito à liberdade de pensamento, consciência e religião, bem assim que o indivíduo tem direito à liberdade de atividade artística, opinião e expressão, em particular de receber e transmitir informações e ideias (BRASIL, 2013).

E no universo da arte, pertinente revisitar as lições de Tolstoi (2011), para quem as criações artístico-culturais não estão presentes apenas nos palcos teatrais, concertos e exposições, mas em toda a extensão da vida humana, como na maneira de se vestir, nas brincadeiras e piadas. Dessa forma, pode-se incluir nesse rol os movimentos reivindicatórios de direitos e garantias individuais e coletivos, de maneira que os atos humanos estão presentes na atividade artística.

Além disso, os direitos culturais, como já visto, estão umbilicalmente ligados à arte em sentido de reciprocidade, de maneira que aqueles, assim como as atividades artísticas, não apenas estão presentes em todas as dimensões dos direitos fundamentais, como ajudaram a produzi-los, até porque sempre contribuíram para o desenvolvimento dos povos.

Por estas razões, há quem sustente que os direitos culturais são direitos complexos e, por isto, estão presentes em todas as dimensões dos direitos fundamentais, os quais foram historicamente gestados com base nos postulados da liberdade, igualdade e solidariedade, lema da Revolução Francesa (REVISTA ITAÚ, 2011).

Nessa marcha, a quarta dimensão dos direitos fundamentais está essencialmente relacionada à ideia do Liberalismo e da globalização, como estágios do sistema capitalista, a partir do qual os bens e serviços são produzidos em função do mercado, gerando riquezas para os donos dos meios de produção. E isto significava cada vez mais a importância do capital na soberania e no poder dos Estados. 
Para Celso Bastos e André Tavares (2000), trata-se de um rol de direitos que decorrem, primeiramente, da superação de um mundo bipolar, polarizado entre os que se alinhavam ao capitalismo e aqueles que adotavam o comunismo como sistema de governo. Ainda, o fenômeno da globalização e os avanços tecnológicos são responsáveis pela ascensão dessa nova categoria de direitos humanos.

$\mathrm{E}$ os chamados direitos fundamentais de quarta dimensão emergiram nesse panorama político, no final do século $\mathrm{XX}$, decorrentes da globalização geopolítica do mundo, que determinaram o surgimento de outra vertente dos direitos fundamentais referentes à democracia, à informação e ao pluralismo político. A propósito, o cientista político Samuel Philips Huntington enxergou a globalização como um processo de expansão da cultura ocidental e do regime capitalista sobre o modo de vida e a produção mundial, o que provocaria um choque de civilizações, como entre a ocidental e o islamismo, por exemplo (HUNTINGTON, 1997).

Uma vez mais, perceba que as manifestações artístico-culturais dos povos, notadamente por meio da religião ou na imposição de sistemas econômicos, determinam a criação dos direitos fundamentais, vez que os acontecimentos são consequência da manifestação do homem, como agente transformador do mundo. Desse modo, os direitos de quarta dimensão são orientados para uma sociedade aberta, no bojo da qual os princípios democráticos e plurais devem realmente servir de farol para a manutenção do Estado de Direito, insculpido na Lei Maior de 1988, por isso, relacionados à ideia de democracia, informação e pluralismo.

A respeito do assunto, José Saramago (2002), em sua obra "O homem duplicado", constrói uma crítica à globalização porque tal fenômeno favorece o progresso das tecnologias, o aumento da produtividade e, até mesmo, o crescimento econômico, todavia provoca também outros efeitos indesejáveis, como a má distribuição de renda e a acentuada desigualdade social. E o autor arremata que a globalização, conquanto imponha uma cultura geral sobre a humanidade, em termos de consumo, moda, música e sistema econômico (capitalismo), na realidade aliena o ser humano, que não se divorcia do individualismo, haja vista que, no final das contas, não aceita o outro igual a si (SARAMAGO, 2002).

Na sequência, a concepção da paz, em sede própria, como direito fundamental de quinta dimensão é defendido por Paulo Bonavides (2017) que, sob uma idealização artístico-cultural, deu seguimento à teoria cunhada pelo jurista tcheco Karel Vasak sobre 
"gerações de direitos fundamentais", a partir de uma aula inaugural ocorrida na cidade francesa de Estrasburgo, em 1979 (BONAVIDES, 2006, p. 563).

A propósito, pertinente o resgate que o professor George Marmelstein (2008, p. 42) fez da aula em que Vasak proferiu em Estrasburgo, utilizando o lema da Revolução Francesa: liberté, égalité e fraternité em relação às gerações dos direitos fundamentais:

a) primeira geração dos direitos seria a dos direitos civis e políticos, fundamentados na liberdade (liberté), que tiveram origem com as revoluções burguesas; b) a segunda geração, por sua vez, seria a dos direitos econômicos, sociais e culturais, baseados na igualdade (égalité), impulsionada pela Revolução Industrial e pelos problemas sociais por ela causados; c) por fim, a última geração seria a dos direitos de solidariedade, em especial o direito ao desenvolvimento, à paz e ao meio ambiente, coroando a tríade com a fraternidade (fraternité), que ganhou força após a Segunda Guerra Mundial, especialmente após a Declaração Universal dos Direitos Humanos, de 1948 (Marmelstein, 2008, p. 42).

Observa-se no fragmento retro que Karel Vasak considerou a paz como direito de terceira dimensão, entrelaçando-a ao espírito de fraternidade. Porém, foi bastante curiosa a ideia de que a quinta dimensão dos direitos fundamentais, introduzida neste século XXI foi, também, buscar fundamento nos ideais da Revolução Francesa, berço do Iluminismo, conforme referenciado preambularmente neste artigo, e de onde brotaram as importantes criações artístico-culturais.

Em síntese, a paz é uma filosofia de vida imprescindível à existência humana, logo, mereceu ser tratada de forma distinta, como assentou o constitucionalista Paulo Bonavides. A partir dela, os povos deram os primeiros passos rumo à vida segura e à convivência socialmente equilibrada, por isso alçou, destacadamente, a um nível qualificado de direito fundamental, como uma garantia necessária à sobrevivência do homem contra o seu próprio instinto bélico.

Além disso, o próprio legislador constitucional de 1988 corroborou com a ideia defendida por Bonavides, de maneira que tratou o tema saúde de forma destacada na Constituição Cidadã, como direito social do trabalhador (art. $6^{\circ}, \mathrm{CF} / 88$ ) e como direito fundamental de todos (art. 196, CF/88) ${ }^{6}$.

\footnotetext{
${ }^{6}$ É oportuno registar ainda que o artigo $2^{\circ}$ da Lei 8.080/1990 dispõe expressamente que a "saúde é um direito fundamental do ser humano, devendo o Estado prover as condições indispensáveis ao seu pleno exercício" (BRASIL, 1990).
} 


\section{CONSIDERAÇÕES FINAIS}

Com base nas razões expostas, extrai-se que a manifestação artístico-cultural expressa o intelecto do homem. Além disso, a criação humana sempre contribuiu para a elevação dos direitos da pessoa humana à categoria de fundamentais, inscritos em Textos Constitucionais. Assim, deflui-se que os direitos elementares do indivíduo foram inspirados originariamente no gênero estético-cultural e assumiram a espécie de norma constitucional em documentos jurídicos, com força normativa, concluindo-se pela relação necessária e simbiótica entre arte, cultura e direito.

O professor Paryson (2001) entende que a arte está presente em toda a vida do indivíduo, por esta razão ela compõe a essência humana, apresentando-se como uma razão de viver, bem assim funciona como um verdadeiro guia orientador das ações do homem. É um verdadeiro estado de natureza e uma terapia para os problemas individuais e coletivos.

E a atividade artístico-cultural e o direito são produtos de uma mesma lógica, sendo certo que a natureza relacional entre esses universos é de retroalimentação, considerando que o direito provém, igualmente, da manifestação humana. Tão verdade que a Constituição Federal de 1988 previu a livre manifestação da atividade artística como direito fundamental, no seu artigo $5^{\circ}$, inciso IX (BRASIL, 2018).

Outro exemplo de que o direito se vale do binômio arte-cultura é dada por Taruffo (2012), na ocasião em que enaltece o ritual concernente aos elementos latu teatrais que caracterizam o trial by jury, que chegam ao conhecimento da sociedade por meio de inúmeros filmes e seriados, em que os advogados batalham sob o olhar dos jurados e na presença de um juiz togado que disciplina a contenda entre as partes processuais.

Ainda na especificidade do tema, Cunha Filho (2018, p. 116-117) adverte que se deve aferir se a Constituição brasileira vigente "disciplina e trata de forma diferenciada os direitos culturais", acrescentando o autor ainda que se deve levar em conta os elementos que lhe dão unidade, a partir de uma "noção de cultura, em sentido estrito e especificamente relacionada ao direito, como sendo um regramento jurídico relativo às artes, à memória de interesse coletivo e aos fluxos formais e informais de saberes".

Com efeito, a ciência jurídica se utiliza essencialmente da atividade artísticocultural para realizar a interpretação de normas, que são produtos da criação do homem. Nesse enlace, a arte e a cultura possuem muitos meios de manifestação, como a escrita, a 
pintura, a música, a literatura, o cinema e outras formas artístico-culturais que revelam e expressam a realidade do mundo; ao passo que o direito, em toda sua extensão, busca o ponto de equilíbrio para a pacificação de conflitos e para a promoção da justiça, recorrendo a diversas formas da expressão humana.

Nessa perspectiva, observa-se que os direitos fundamentais, na dimensão e importância jurídica que recebeu na fase contemporânea, surgiram durante o Século das Luzes, no período pós-Revolução Francesa, que livrou o mundo do obscurantismo, cujos ideias protetores foram impulsionados sobretudo por intelectuais, escritores, pintores, músicos, cineastas que promoveram a arte e a cultura humana.

A partir daí, as dimensões dos direitos fundamentais sofreram influências das ideias artístico-revolucionárias ocorridas na Europa do século XVIII, especialmente em relação aos fundamentos de liberdade, igualdade e fraternidade que orientaram o surgimento dos direitos fundamentais. Por isso, restou evidente a contribuição do sentimento artísticocultural do homem na formação de mecanismos jurídicos, chamados de direitos fundamentais, que coroaram a frutuosa ligação entre a arte, a cultura e o direito.

Portanto, as manifestações artístico-culturais que dominaram a Europa e o Ocidente, a partir do século XVIII, contribuíram na formação da primeira dimensão dos direitos fundamentais da pessoa humana, bem assim influenciaram os Estados soberanos a ampliarem essas garantias formais nos anos que se seguiram, no âmbito de suas jurisdições. E esta necessidade de permanente valorização e evolução dos direitos fundamentais é um imperativo, com base na teoria de que não se admitem retrocessos.

\section{REFERÊNCIAS}

ALEXY, Robert. Colisão de direitos fundamentais e realização de direitos fundamentais no Estado de Direito Democrático. Revista de Direito Administrativo, Rio de Janeiro, v. 217, 2015. Disponível em:

http://bibliotecadigital.fgv.br/ojs/index.php/rda/article/view/47414/45316. Acesso em: 10 de ago de 2021.

ANDRADE, Carlos Drummond de. A Rosa do Povo. São Paulo: Companhia das Letras, 2012.

BASTOS, Celso Ribeiro; TAVARES, André Ramos. Tendências do direito público no limiar de um novo milênio. 1. ed. São Paulo: Saraiva, 2000. 
BOBBIO, Norberto. A Era dos Direitos. Rio de Janeiro: Campus, 1992.

BONAVIDES, Paulo. Curso de Direito Constitucional. 32 ed. Atual. São Paulo: Malheiros, 2017.

BONAVIDES, Paulo. Curso de Direito Constitucional. $19^{\text {a }}$ Edição, São Paulo: Editora Malheiros, 2006.

BRASIL. Direitos Humanos. 4a ed. Brasília: Senado Federal, Coordenação de Edições Técnicas, 2013.

BRASIL. Supremo Tribunal Federal (STF). A Constituição e o Supremo [recurso eletrônico] / Supremo Tribunal Federal. - 6. ed. atual. até a EC 99/2017. - Brasília: STF, Secretaria de Documentação, 2018.

BRASIL. Lei $\mathrm{n}^{\circ}$ 8.080, de 19 de setembro de 1990. Dispõe sobre as condições para a promoção, proteção e recuperação da saúde, a organização e o funcionamento dos serviços correspondentes e dá outras providências. DOU. Brasília, DF, 20 set. 1990. Disponível em: http://www.planalto.gov.br/ccivil_03/leis/18080.htm. Acesso em: 25 ago. 2021.

CANOTILHO, José Joaquim Gomes. Estudos sobre Direitos Fundamentais. São Paulo: Revista dos Tribunais. Portugal: Coimbra, 2008.

CUNHA FILHO, Francisco Humberto. Teoria dos direitos culturais: fundamentos e finalidades. São Paulo: Edições Sesc São Paulo, 2018.

DOLHNIKOFF, Luis. Voltaire, Rousseau, Maistre, Stendhal, Balzac, Baudelaire, Mallarmé, Maupassant, Proust: os franceses. São Paulo: Editora Hedra, 2015.

HUNTINGTON, Samuel Philips. O choque das civilizações e a recomposição da nova ordem mundial. Rio de janeiro: Objetiva, 1997.

KANT, Immanuel. Crítica del discernimiento. Edición y traducción de Roberto R. Aramayo y Salvador Mas. A. Machado Libros. Madrid: 2003.

MARMELSTEIN, George. Curso de direitos fundamentais. São Paulo: Altas, 2008.

MENDONÇA, Camila. Arte na pré-história: paleolítico, neolítico e idade do metais. Educa Mais Brasil, Brasília/DF, 30 jan. 2019. Semanal. Disponível em: https://www.educamaisbrasil.com.br/enem/artes/arte-na-pre-historia. Acesso em: 5 ago. 2021. 
REVISTA OBSERVATÓRIO ITAÚ CULTURAL. OIC. n. 11 (jan./abr. 2011) - São Paulo, SP: Itaú Cultural, 2011.

SILVA, José Afonso da. Curso de Direito Constitucional Positivo. 19 ed. rev, e atual. São Paulo: Malheiros, 2001.

SILVA, José Afonso da. Curso de direito constitucional positivo. 22. ed. São Paulo: Malheiros, 2003.

SILVA, Virgílio Afonso. A constitucionalização do Direito: os direitos fundamentais nas relações entre particulares. São Paulo: Malheiros, 2005.

SARLET, Ingo Wolfgang. A Eficácia dos Direitos Fundamentais. $8^{\mathrm{a}}$ Edição, Porto Alegre: Livraria do Advogado - Ed., 2007.

SARMENTO, Daniel. Direitos Fundamentais e Relações Privadas. $2^{a}$ Edição. Rio de Janeiro: Editora Lumen Juris, 2006.

RODAS, Sergio. Constituição alemã de Weimar inovou ao estabelecer direitos sociais: aniversário de 100 anos. Consultor Jurídico, São Paulo, 2019. Diário. Disponível em: https://www.conjur.com.br/2019-ago-06/constituicao-weimar-inovou-estabelecerdireitos-sociais. Acesso em: 12 ago. 2021.

ROUSSEAU, Jean-Jacques. Discurso Sobre Las Ciencias y Las Artes. Madrid: Alba, 1999.

SARAMAGO, José. O homem duplicado. São Paulo: Companhia das Letras, 2002.

TARUFFO, Michele. Uma simples verdade: o juiz e a construção dos fatos. Trad. Vitor de Paula Ramos. São Paulo: Marcial Pons, 2012.

TOLSTOI, Leon. O que é a arte? São Paulo: editora Ediouro, 2002.

TOLSTOI, Liev. O que é arte? In: Os últimos dias. São Paulo: Companhia das Letras; Penguin, 2011.

XEREZ, Rafael Marcílio. Concretização dos direitos fundamentais: teoria, método, fato e arte. Rio de Janeiro: Lumen Juris, 2014. 